\title{
EFFECT OF MASS MATRIX FORMS ON NUMERICAL SIMULATIONS RESULTS IN HEAT CONDUCTION MODELING
}

\author{
Maria Zych \\ Institute of Computer and Information Science, Częstochowa Universisty of Technology \\ Czestochowa, Poland \\ maria.zych@icis.pcz.pl
}

\begin{abstract}
The paper presents an analysis of the impact of the mass matrix on the changes in temperature during the computer simulation (using the method of finite elements) of the heat conduction process. The temperature variations of the phenomenon was taken into consideration, which is required during the solidification simulation of binary alloys. It was shown that the smallest oscillation occurs in the lumped matrices in the initial stage of the simulation. The results for lumped and diagonal matrix are mostly equal.
\end{abstract}

Keywords: heat conduction, temperature changes, the matrix

\section{Introduction}

The heat flux is described by Fourier's first law:

$$
q=-\lambda \nabla T
$$

where: $q$ - heat flux, $\lambda$ - the thermal conductivity, $\nabla$ - the gradient, $T$ - the temperature

The heat flow is described by the Fourier's equation:

$$
\nabla \cdot(\lambda \nabla T)=c \rho \frac{\partial T}{\partial t}
$$

where $T$ - the temperature, $t$ - the time, $\lambda$ - the thermal conductivity, $\rho$ specific heat, $c$ - thermal conductivity $[1,2]$.

By using the finite element method, the equation (2) changes into the system of algebraic equations. As a result of the necessary transformations, the ordinary differential equation containing a derivative with respect to time is obtained:

$$
\mathbf{K T}+\mathbf{M} \dot{\mathbf{T}}=\mathbf{b}
$$


where $\mathbf{K}$ is the conductance matrix, $\mathrm{M}$ is the mass matrix (also referred to as a capacity matrix), $\mathrm{T}$ the vector of temperature, and $\mathrm{b}$ is a vector of the node source (so -called vector of the boundary conditions).

\section{Boundary conditions}

The problem of the heat conduction belongs to the initially-boundary issues. Initial conditions are used to impart certain values at the initial moment. Four types of boundary conditions that are associated with a complex heat exchange are distinguished [1].

The first kind of the boundary condition (Dirichlet): on the boundary $\Gamma$ of the area $\Omega$ is the temperature $\left(T_{z}\right)$

$$
\Gamma: T=T_{z}
$$

The boundary condition of the second kind (Neumann): on the boundary $\Gamma$ of the area $\Omega$ is the heat flux $\left(q_{z}\right)$

$$
\Gamma: q=q_{z}
$$

The third type of boundary condition (Newton): on the boundary $\Gamma$ of the area $\Omega$ the heat exchange with the environment occurs:

$$
\Gamma: q=a\left(T-T_{o t}\right)
$$

where $\alpha$ is the coefficient of heat exchange with the environment, $T$ is the temperature of the body on the boundary $\Gamma$ and $T_{o t}$ is the ambient temperature, $q$ is the heat flux entering $\left(T<T_{o t}\right)$ into the area $\Omega$ or the effluent $\left(T>T_{o t}\right)$ from the area $\Omega$.

The fourth type of boundary condition (continuity condition): on the boundary $\Gamma$ separating the areas $\Omega 1$ and $\Omega 2$ flow of heat occurs. There are two cases for this boundary condition:

- ideal contact

$$
\Gamma:\left\{\begin{aligned}
(\mathbf{n} \cdot \lambda \nabla T)^{(1)} & =(\mathbf{n} \cdot \lambda \nabla T)^{(2)} \\
T^{(1)} & =T^{(2)}
\end{aligned}\right\}
$$

where $\boldsymbol{n}$ is the normal vector to the $\Gamma$ boundary,

- no perfect contact (contact through an additional layer) 


$$
\Gamma:\left\{\begin{array}{c}
-(\mathbf{n} \cdot \lambda \nabla T)^{(1)}=-(\mathbf{n} \cdot \lambda \nabla T)^{(2)}=\frac{\lambda_{p}}{\delta}\left(T^{(1)}-T^{(2)}\right) \\
T^{(1)} \neq T^{(2)}
\end{array}\right\}
$$

where $\lambda_{p}$ is the coefficient of thermal conductivity of the material of the separation layer, $\delta$ is the thickness of this layer, $\mathbf{n}$ is the normal vector.

\section{The analytical solution}

For the analysis of the accuracy of numerical simulations, the analytical solution was used in order to compare the coagulation curves. The analytical solution of the heat conduction equation describing changes in temperature in the control region in the interval $[0, \mathrm{~L}]$ has the following form $[3]$ :

$$
\lambda \frac{\partial^{2} \mathrm{~T}(x, t)}{\partial x^{2}}-\rho c \frac{\partial \mathrm{T}(x, t)}{\partial t}-\rho c \frac{\partial \mathrm{T}(x, t)}{\partial x} V_{x}(x)=0, x \in[0, \mathrm{~L}]
$$

For the purpose of the tasks, the initial condition $T(x, t=0)=T_{0}$ and the boundary conditions were assumed: $\mathrm{T}(x=0, t)=\mathrm{T}_{z}$ on the initial boundary, $q(x=L, t)=0$ on the opposite boundary.

Assuming that the thermophysical quantities $\lambda, \rho, c$ are identical in every point of the area and fixed in the whole calculations cycle, the analytical solution has the following form:

$$
\left.\frac{T(x, t)-T_{0}}{T_{z}-T_{0}}=\frac{1}{2}\left(\operatorname{erfc}\left(\frac{x}{\sqrt{4 a t}}\right)\right)+\operatorname{erfc}\left(\frac{x}{\sqrt{4 a t}}\right)\right)
$$

After considering the initial and boundary conditions, the following formula was obtained:

$$
T\left(x, t_{i}\right)=\operatorname{erfc}\left(\frac{x}{{\sqrt{4 a t_{i}}}_{i}}\right)\left(T_{z}-T_{0}\right)+T_{0}
$$

where $a$ is the coefficient of temperature compensation [4].

\section{Results}

In the computer simulations, three forms of mass matrix (full, diagonal, lumped) [5] were used in order to verify their impact on numerical calculations. 
Changes in temperature in the 2D mesh shown in Figure 1 were examined and compared.

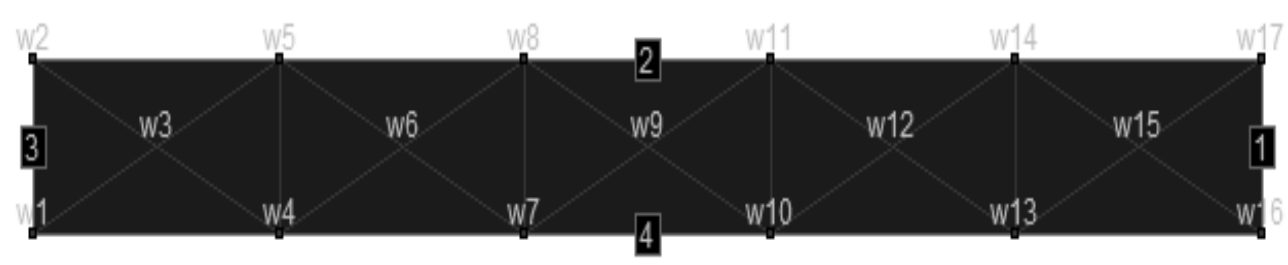

Fig. 1. Contemplated mesh of triangular finite elements

The first kind of boundary condition of temperature $T_{z}=0 \mathrm{~K}$ was introduced into the 3rd boundary. The second kind of boundary condition of heat flux $q_{\mathrm{z}}=0 \mathrm{~W} / \mathrm{m}^{2}$ was introduced into the 1 st boundary. The initial temperature was $T_{0}=400 \mathrm{~K}$,

The following material properties and parameters of the calculation were used: $\rho=7500 \mathrm{~kg} / \mathrm{m}^{3}, c=620 \mathrm{~J} /(\mathrm{kg} \cdot \mathrm{K}), \lambda=40 \mathrm{~W} /(\mathrm{m} \cdot \mathrm{K}), \Delta t=0.05 \mathrm{~s}$, the number of calculation steps $=1000$, control length $L=10 \mathrm{~cm}$.

Due to the specific nature of the 2D area, numerical results can be compared with analytical results obtained for functions of one variable.

The following mass matrices form was used in the numerical calculation $[6,7]$ :

- full:

$\mathrm{a} / 12\left[\begin{array}{lll}2 & 1 & 1 \\ 1 & 2 & 1 \\ 1 & 1 & 2\end{array}\right]$

- diagonal:

$\mathrm{a} / 12\left[\begin{array}{lll}1 & 0 & 0 \\ 0 & 4 & 0 \\ 0 & 0 & 1\end{array}\right]$

- lumped:

$\mathrm{a} / 3\left[\begin{array}{lll}1 & 0 & 0 \\ 0 & 1 & 0 \\ 0 & 0 & 1\end{array}\right]$

where $\mathrm{a}$ is the area of the considered finite element. 
In this study, differences in temperature changes to a time step depending upon the matrix have been observed.

The graphs present the results of the analytical solution and original program in which the following matrices were considered: full, diagonal and lumped. Each of the charts shows four different cases of the cooling curves for selected nodes in the mesh of finite elements.

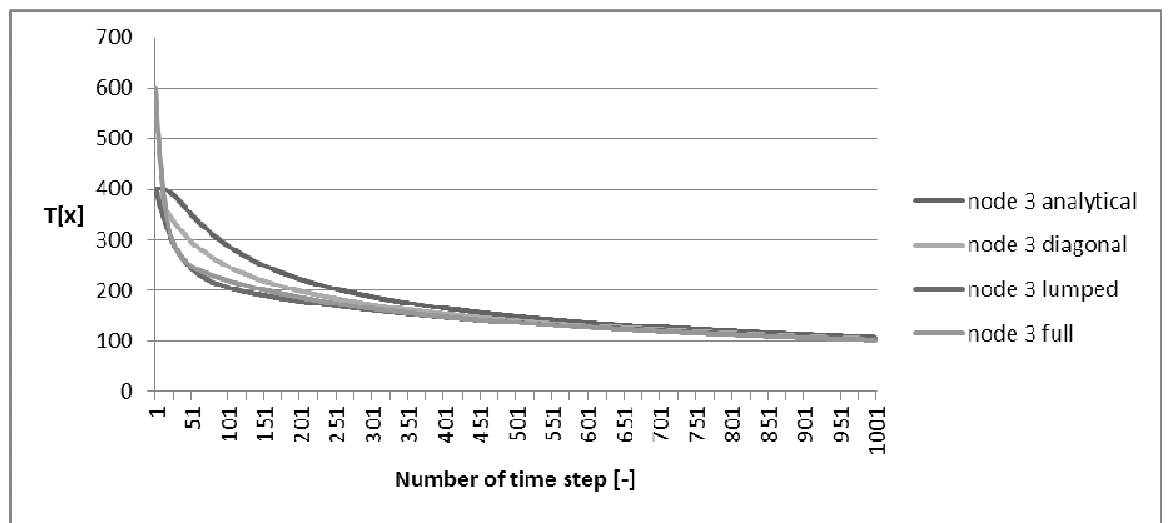

Fig. 2. Temperature dependency on the time for node 3

The cooling curve for node 3 in the initial phase shows small oscillations for a full matrix (Fig. 2). The lumped matrix, diagonal and analytical solution do not cause oscillations in the initial phase. Lumped matrix and the diagonal matrix achieved similar results to the analytical solution. From about the $400^{\text {th }}$ step, the numbers of temporary matrices and analytics solution are coincided.

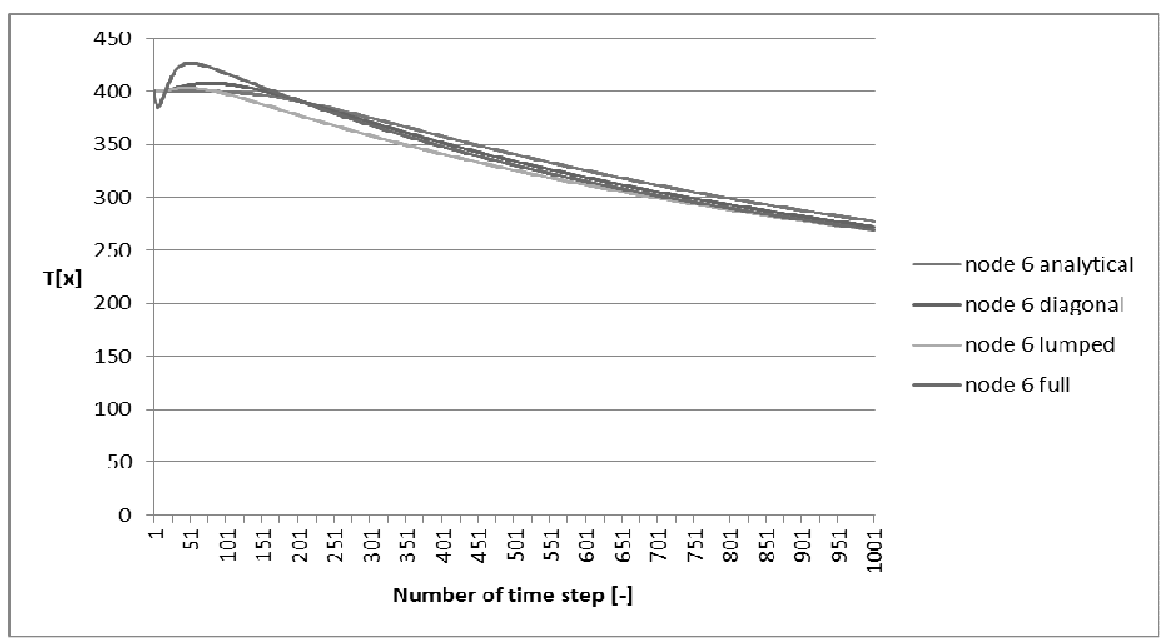

Fig. 3. Temperature dependency on the time for node 6 
The cooling curve for node 6 (Fig. 3) of the full matrix shows higher oscillation than for node 3 and there are small temperature fluctuations. The numerical calculations for a diagonal matrix show a multi-stage temperature rise in the initial phase. The lumped matrix provides similar results with the analytical solution in the initial phase of time steps. Calculations for subsequent time steps of the matrices and analytical solutions are coincided.

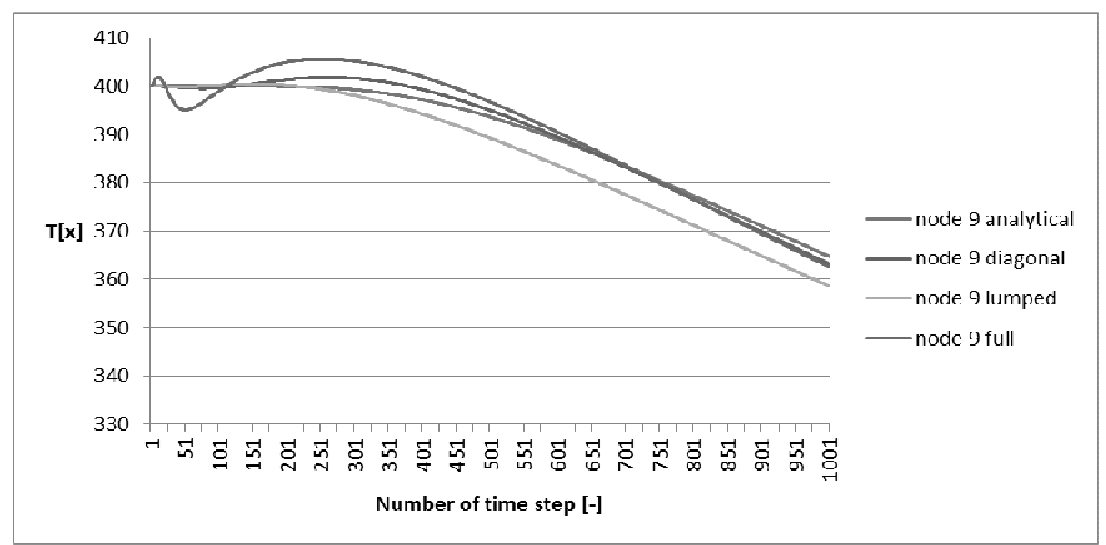

Fig. 4. Temperature dependency on the time for node 9

The cooling curve for node 9 (Fig. 4) for the full matrix shows even greater oscillation and temperature fluctuations in the initial phase than in the case of node 6. The temperature jump can be observed in the diagonal matrix. In the initial phase, the lumped matrix coincides with the analytical solution. The lumped matrix shows the least oscillating results. The analytical solution of the time step is equal to 632 coincides with the full and diagonal matrices.

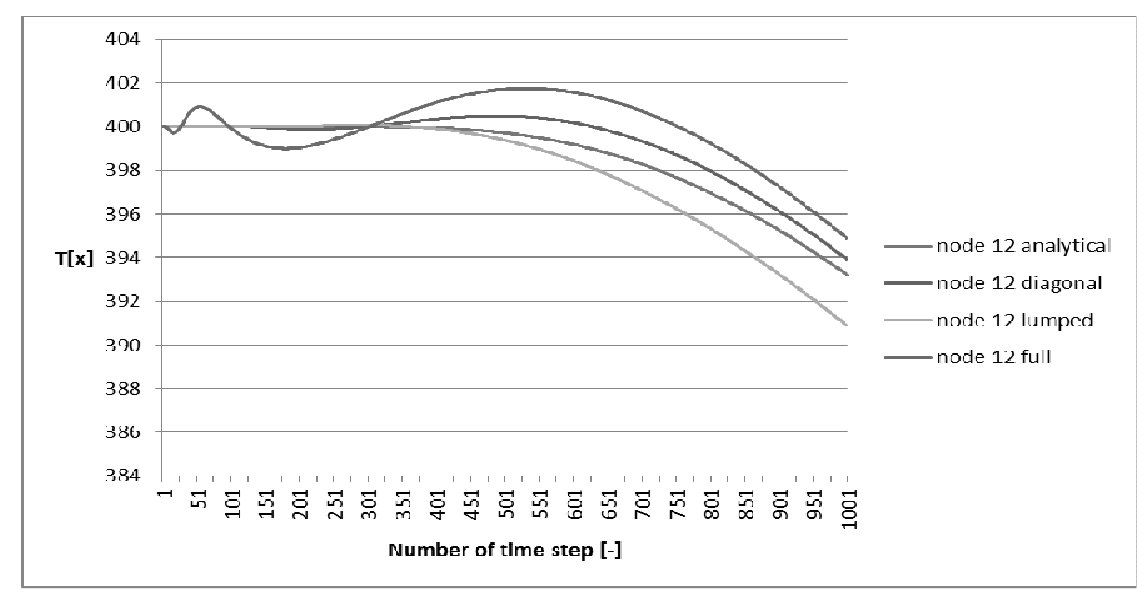

Fig. 5. Temperature dependency on the time for node 12 
The cooling curve for node 12 causes oscillation of the full matrix (Fig. 5). In the initial phase, the diagonal and the lumped matrices coincide with the analytical solution. Around the $300^{\text {th }}$ time step shows the differences in temperature [ 1 or 2 degree(s)] between the matrices and the analytical solution.

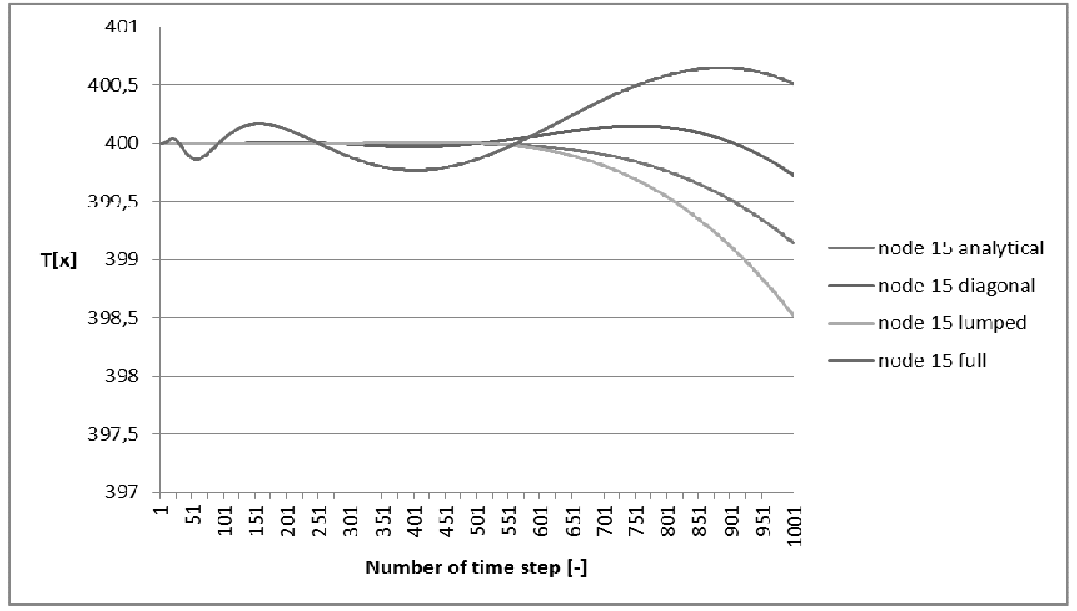

Fig. 6. Temperature dependency on the time for node 15

The cooling curve of the node 15 (Fig. 6) for the full matrix causes oscillations and jumps in nearly all of the time steps. Around the $500^{\text {th }}$ time step the lumped matrix, diagonal matrix, and analysis solution are coincided. In the subsequent time steps, matrices are divergent from each other and from the analytical solution.

\section{Conclusions}

On the basis of the calculations, it can be concluded that the lumped matrix is the most suitable for numerical calculation because it causes the lowest oscillations and the obtained results are the most similar to the analytical solution. The conducted calculations show that the full matrix is the one which causes the greatest oscillation during numerical and temperature fluctuations. The diagonal matrix obtained intermediate results between the full and the lumped matrix. Accordingly, the lumped matrix is the most appropriate matrix for the numerical calculation.

This analysis will be helpful in selecting the appropriate form of a matrix in numerical modeling of more complex issues, such as coagulation, cracking and formation of contraction cracks [8-10].

\section{References}

[1] Sczygiol N., Modelowanie numeryczne zjawisk termomechanicznych w krzepnącym odlewie i formie odlewniczej, Wydawnictwo Politechniki Częstochowskiej, Częstochowa 2000. 
[2] Sczygiol N., Szwarc G. Application of enthalpy formulations from numerical simulation of castings solidification. Computer Assisted Mechanics and Engineering Sciences 2011, 8, 99-120.

[3] Gawrońska E., Sczygiol N., Stability of the mixed time partitioning methods in relation to the size of time step, Special Issue: 82nd Annual Meeting of the International Association of Applied Mathematics and Mechanics (Gesellschaft für Angewandte Mathematik und Mechanik), GAMM'2011, 18-21 April 2011, Graz, Austria, 467-468.

[4] Kulawik A., Modelowanie zjawisk obróbki cieplnej stali średniowęglowych. Wydawnictwo Politechniki Częstochowskiej, Częstochowa 2013.

[5] Gawrońska E., Sczygiol N., Application of mixed time partitioning methods to raise the efficiency of solidification modeling, 12th International Symposium on Symbolic and Numeric Algorithms for Scientific Computing, SYNASC'2010, 23-26 September 2010, Timisoara, Romania, 99-103.

[6] Shen R. Wu, Lumped mass matrix in explicit finite element method for transient dynamics of elasticity, Comput. Methods Appl. Mech. Engrg. 2006, 195, 5983-5994.

[7] Wood W.L., Partical Time-setepping Schemes, Clarendon Press, Oxford 1990.

[8] Gawronska E., Sczygiol N., Numerically Stable Computer Simulation of Solidification: Association Between Eigenvalues of Amplification Matrix and Size of Time Step, Transactions on Engineering Technologies, Springer Netherlands 2015, 17-30.

[9] Gawronska E., Sczygiol N., Relationship between eigenvalues and size of time step in computer simulation of thermomechanics phenomena, International MultiConference of Engineers and Computer Scientists, IAENG 2014, 12-14 March 2014, Hong Kong, 881-885.

[10] Wodo O., Gawronska E., Modeling of two-stage solidification: Part II Computational verification of the model, Archives of Foundry Engineering Vol.13, Issue 1, January - March 2013, 125-130. 